\title{
Ganho de peso, característica da carcaça e dos demais componentes corporais de cordeiros confinados, alimentados com distintos teores de uréia ${ }^{1}$
}

\author{
Weight gain, carcass traits and other body components from feedlot lambs, fed diets \\ with different levels of urea
}

\author{
Pedro Paulo Sobolow de Souza ${ }^{2}$ Edson Ramos de Siqueira ${ }^{3}$ Sirlei Aparecida Maestá ${ }^{4}$
}

\section{RESUMO}

\begin{abstract}
A presente pesquisa teve por objetivo avaliar o desempenho, características das carcaças e componentes não constituintes da carcaça de cordeiros confinados, submetidos a uma dieta convencional, com outras três, que tiveram a fonte de proteína verdadeira substituída por níveis crescentes de uréia. Utilizaram-se 48 cordeiros inteiros, mestiços Ile de France $x$ Corriedale, desmamados aos 70 dias de idade. A recria e a terminação foram efetuadas em regime de confinamento total, $e$ os animais foram distribuídos, aleatoriamente, em quatro grupos com distintos níveis de uréia $(0 ; 0,4 ; 0,8$ e 1,2\% da matéria seca total). Os animais foram abatidos ao redor de $32 \mathrm{~kg}$ de peso vivo. Não foram observadas diferenças significativas entre os tratamentos para as variáveis: ganho de peso médio diário, peso vivo ao abate, pH muscular (0 e 45 minutos e 24 horas após o abate), pesos da carcaça quente e fria, porcentagem de perda de peso ao resfriamento, rendimentos comercial e verdadeiro, pesos dos componentes não constituintes da carcaça, condição corporal, conformação e acabamento. Entretanto, para peso da pele, o nível 0\%, diferiu do nível 0,8\%. Para as variáveis, morfometria e proporção dos cortes das carcaças, não foram observadas diferenças entre os níveis de uréia. O comprimento da perna (cm) dos cordeiros com nível de 0,8\%, foi inferior ao do nível $0 \%$. Na variável índice de compacidade da perna, o nível $0,8 \%$, diferiu dos níveis 0 e 0,4\%. Concluiu-se que a utilização da uréia nos teores apresentados na presente pesquisa, é uma prática viável, não tendo afetado variáveis consideradas.
\end{abstract}

Palavras-chave: ovinos, alimentação, desempenho, carne.

\section{ABSTRACT}

This trial was carried out to evaluate performance, carcass traits and non-carcass components of lambs fed with a conventional diet plus other three diets with crescent levels of urea in substitution of a true protein source. 48 crossbred male lambs (Ile de France $x$ Corriedale) weaned at 70 days of age were used. They grew and were finished in feedlot randomly allocated in four groups according to urea levels $(0.0 ; 0.4 ; 0.8$ and $1.2 \%$ of total dry matter). Animals were slaughtered with 32 $\mathrm{kg}$ of live weight. There was no difference among urea levels for the following parameters: daily weight gain, live weight at slaughter, hot and chilled carcass weights, percentage of weight losses during chilling, commercial and biological carcass dressing out, non-carcass components weights, body condition and conformation, and fat deposition. However, for the skin weight ( $\mathrm{kg}$ ) the $0.0 \%$ level was lower than the $0.8 \%$ level. There were not observed differences among treatments for the following variables: muscle $\mathrm{pH}$ at three moments, morphometric and carcass cut proportions. The leg length of the lambs fed diet with $0.8 \%$ urea was lower than that of $0.0 \%$ level. For leg compacity, $0.8 \%$ was smaller than the leg length of those fed with $0.0 \%$ urea. It was concluded that growing levels of urea utilization is viable and did not affect the variables that were analyzed in this work.

Key words: sheep, alimentation, performance, meat.

\section{INTRODUÇÃO}

No estado de São Paulo, em função dos problemas apresentados decorrentes do sistema de criação extensivo, principalmente em relação à verminose, tem-se preconizado a terminação de cordeiros em confinamento. Neste sistema, a alimentação é muito importante, sendo o fator que mais onera o custo de produção (FURUSHO, 1995). Assim,

\footnotetext{
${ }^{1}$ Parte da Dissertação de Mestrado do primeiro autor apresentada ao Programa de Pós-graduação em Nutrição e Produção Animal da Faculdade De Medicina Veterinária e Zootecnia (FMVZ), Universidade Estadual Paulista (UNESP), Botucatu, SP.

${ }^{2}$ Zootecnista, aluno de Pós-graduação em Nutrição e Produção Animal, FMVZ, UNESP, 18600-000, Botucatu, SP. E-mail: sobolow@fesurv.br. Autor para correspondência.

${ }^{3}$ Professor Titular, FMVZ, UNESP, 18600-000, Botucatu, SP. E-mail: ersiqueira@ fca.unesp.br

${ }^{4}$ Aluno de Pós-graduação, FMVZ, UNESP, Botucatu, SP. E-mail: sirleimaesta@ hotmail.com
} 
é necessário melhorar o desempenho dos cordeiros e estabelecer dietas com custo mínimo, para que se consiga viabilidade econômica da produção. A utilização de alimentos alternativos, em substituição aos ingredientes mais caros, é uma saída para diminuir custos com a alimentação de cordeiros (GARCIA 1998). Tem-se procurado utilizar subprodutos da agroindústria (FURLAN, 1988), ou compostos nitrogenados não protéicos, entre os quais se destaca a uréia. Entretanto, a alimentação pode alterar as características qualitativas da carcaça e da carne ovina (SAÑUDO, 1993) e, por essa razão, pesquisas são necessárias para se saber a real viabilidade da utilização dos distintos alimentos. Apesar de aproximadamente $70 \%$ dos resultados existentes sobre a avaliação nutritiva de dietas para ruminantes terem sido obtidos com ovinos, são muito escassas as informações sobre o desempenho produtivo da espécie, quando arraçoada com alimentos não convencionais, principalmente em sistemas de alta produção (FURLAN, 1988). Sendo assim, esse estudo teve como objetivo avaliar os efeitos do uso da uréia sobre o desempenho, características da carcaça e dos demais componentes corporais de cordeiros confinados, bem como os custos das dietas.

\section{MATERIAL E MÉTODOS}

O experimento foi realizado no Setor de Ovinos e no Laboratório de Carnes do Departamento de Produção e Exploração Animal da FMVZ (Faculdade de Medicina Veterinária e Zootecnia)-UNESP (Universidade Estadual Paulista), Botucatu- SP.

Foram utilizados 48 cordeiros inteiros, mestiços Ile de France x Corriedale, desmamados aos
70 dias de idade, quando então se iniciou o período de adaptação dos animais à uréia. Nos primeiros quinze dias, quatro lotes com 12 cordeiros cada um, consumiram ração com $0 \%$ de uréia. A partir do $16^{\circ}$ dia, os cordeiros dos níveis de uréia 0,$4 ; 0,8$ e 1,2\%, passaram a consumir ração com $0,4 \%$ de uréia por 3 dias. Após o $19^{\circ}$ dia, os cordeiros alimentados com os níveis de uréia de 0,8 e 1,2\%, receberam ração com $0,8 \%$ de uréia por três dias. E, finalmente, a partir do $22^{\circ}$ dia, os cordeiros do nível de uréia $1,2 \%$, iniciaram o consumo da ração com $1,2 \%$ de uréia. A recria e terminação foi realizada em regime de confinamento total e os animais foram distribuídos aleatoriamente nos quatro tratamentos, com dietas isoprotéicas (16,45\% de proteína bruta) e isocalóricas $(67,60 \%$ de nutrientes digestíveis totais) fornecidas à vontade (Tabela 1).

A pesagem foi realizada semanalmente, até que os animais atingissem o peso de $32 \mathrm{~kg}$, quando foram abatidos. No dia anterior ao abate, os cordeiros foram transportados para o abatedouro, onde permaneceram em dieta hídrica por aproximadamente 18 horas. Antes do abate foram pesados (peso vivo ao abate) e avaliados quanto à sua condição corporal, mediante palpação da região lombar, com atribuição de notas de 1 a 5 ( 1 para excessivamente magro e 5 para excessivamente gordo, com escala de 0,25 ).

Logo após o abate, foram registrados os pesos do sangue, pele, patas, cabeça e vísceras, individualmente (componentes não constituintes da carcaça). Efetuou-se o esvaziamento do trato gastrintestinal, e obteve-se o peso corporal vazio (peso vivo ao abate menos o peso do conteúdo gastrintestinal), determinando-se o rendimento verdadeiro das carcaças, que é a relação entre o peso

Tabela 1 - Composição percentual das dietas experimentais (\% na matéria seca).

\begin{tabular}{lcccc}
\hline & \multicolumn{3}{c}{ RAÇÃO } \\
\cline { 2 - 4 } INGREDIENTES & 1 & 2 & 3 & 4 \\
\hline Feno B. decumbens & 40,00 & 40,00 & 40,00 & 40,00 \\
Milho & 26,20 & 28,96 & 31,60 & 34,20 \\
Farelo de soja & 22,50 & 21,00 & 19,80 & 2,96 \\
Farelo de algodão & 7,70 & 6,00 & 4,12 & 1,50 \\
Óleo vegetal & 1,50 & 1,50 & 1,50 & 1,20 \\
Uréia & 0,00 & 0,40 & 0,80 & 0,12 \\
Enxofre & 0,00 & 0,04 & 0,08 & 1,10 \\
Calcário calcítico & 1,10 & 1,10 & 1,10 & 1,00 \\
Mistura Mineral ${ }^{*}$ & 1,00 & 1,00 & 1,00 & \\
\hline
\end{tabular}

* Composição da mistura mineral por kg de produto: $\mathrm{P}=75 \mathrm{~g} ; \mathrm{Ca}=120 \mathrm{~g} ; \mathrm{Na}=160 \mathrm{~g} ; \mathrm{Cl}=240 \mathrm{~g} ; \mathrm{S}=20 \mathrm{~g} ; \mathrm{Mg}=13 \mathrm{~g} ; \mathrm{Zn}=6.000 \mathrm{mg} ; \mathrm{Cu}=$ $550 \mathrm{mg} ; \mathrm{Fe}=2.000 \mathrm{mg} ; \mathrm{Mn}=2.000 \mathrm{mg} ; \mathrm{Co}=130 \mathrm{mg} ; \mathrm{I}=120 \mathrm{mg} ; \mathrm{Se}=20 \mathrm{mg} ; \mathrm{F}=750 \mathrm{mg} ;$ Palatabilizante $=50 \mathrm{~g}$. 
da carcaça quente e o peso corporal vazio (SAÑUDO \& SIERRA, 1986). O pH do músculo Longissimus dorsi foi registrado logo após o abate, 45 minutos depois, e após o resfriamento por $24 \mathrm{~h} \mathrm{a} 4^{\circ} \mathrm{C}$.

Após a obtenção do peso quente, as carcaças foram resfriadas a $4^{\circ} \mathrm{C}$, por 24 horas, quando se registrou o peso da carcaça fria. Obteve-se então, a porcentagem de perda de peso ao resfriamento e o rendimento comercial (relação entre o peso da carcaça fria e o peso vivo ao abate). As carcaças foram avaliadas subjetivamente, segundo metodologia citada por COLOMER-ROCHER (1988), considerando-se as seguintes variáveis: grau de gordura: determinado mediante apreciação visual, utilizando-se uma escala de 5 pontos, sendo o valor 1 para as excessivamente magras e 5 para as excessivamente gordas; - conformação: avaliação visual da carcaça, considerando-a como um todo, levando-se em consideração as diferentes regiões anatômicas, e a espessura de seus planos musculares e adiposos em relação ao tamanho do esqueleto que a suporta, sendo o valor 1 atribuído à conformação muito pobre, e 5 para a excelente.

Foram realizadas as seguintes medidas:

- comprimento externo da carcaça (CEC); comprimento interno da carcaça (CIC); comprimento da perna $(\mathrm{CP})$; perímetro da garupa $(\mathrm{PG})$; largura da garupa (LG) e profundidade torácica (PT).

Calcularam-se os índices de compacidade da carcaça, que é dado pelo peso da carcaça fria dividido pelo comprimento interno da carcaça $(\mathrm{kg} / \mathrm{cm})$ e o da perna, que consiste na largura da garupa dividida pelo comprimento da perna $(\mathrm{cm} / \mathrm{cm})$. Posteriormente, as carcaças foram divididas ao meio, sendo a meia carcaça esquerda seccionada em 7 cortes principais: pescoço; paleta; costelas descobertas; costelas; baixos; lombo; perna, que foram pesados individualmente (COLOMER-ROCHER \& ESPEJO, 1972).

A área do músculo Longissimus dorsi foi determinada com planímetro, e sobre sua superfície foram efetuadas as medidas abaixo relacionadas: medida A ou largura máxima do músculo, medida B ou profundidade máxima do músculo, ambas tomadas com régua; medida $\mathrm{C}$ ou espessura de gordura sobre $\mathrm{o}$ músculo, e medida $\mathbf{J}$ ou maior espessura de gordura de cobertura no perfil do lombo, medidas com paquímetro (COLOMER-ROCHER \& ESPEJO, 1972).

O delineamento experimental foi $\mathrm{O}$ inteiramente casualizado e os dados foram analisados estatisticamente através do programa Statistic Analysis System (SAS, 1986), sendo as médias comparadas entre si pelo Teste de Tukey, $(\mathrm{P}<0,05)$.

\section{RESULTADOS E DISCUSSÃO}

O ganho de peso médio diário (Tabela 2) foi considerado bom e compatível com as dietas utilizadas, não tendo diferido $(\mathrm{P}<0,05)$ entre os níveis de uréia, concordando com os resultados de

Tabela 2 - Médias e desvios-padrão para ganho médio de peso, pH muscular, características da carcaça e componentes corporais de cordeiros terminados com diferentes níveis de uréia.

\begin{tabular}{|c|c|c|c|c|}
\hline \multicolumn{5}{|c|}{ Níveis de uréia (\% na MS) } \\
\hline Variáveis & 0 & 0,4 & 0,8 & 1,2 \\
\hline Ganho médio de peso diário (kg) & $0,24 \pm 0,04^{\mathrm{a}}$ & $0,22 \pm 0,04^{\mathrm{a}}$ & $0,22 \pm 0,02^{\mathrm{a}}$ & $0,22 \pm 0,02^{\mathrm{a}}$ \\
\hline Peso vivo ao abate $(\mathrm{kg})$ & $31,87 \pm 0,49^{\mathrm{a}}$ & $32,47 \pm 1,07^{\mathrm{a}}$ & $32,06 \pm 0,98^{\mathrm{a}}$ & $32,10 \pm 2,74^{\mathrm{a}}$ \\
\hline \multicolumn{5}{|l|}{ pH muscular } \\
\hline Omin. & $7,11 \pm 0,18^{\mathrm{a}}$ & $7,21 \pm 0,28^{\mathrm{a}}$ & $7,17 \pm 0,24^{\mathrm{a}}$ & $7,26 \pm 0,23^{\mathrm{a}}$ \\
\hline $45 \mathrm{~min}$. & $6,85 \pm 0,15^{\mathrm{a}}$ & $6,78 \pm 0,18^{\mathrm{a}}$ & $6,73 \pm 0,15^{\mathrm{a}}$ & $6,76 \pm 0,28^{\mathrm{a}}$ \\
\hline $24 h$ & $5,64 \pm 0,34^{\mathrm{a}}$ & $5,86 \pm 0,34^{\mathrm{a}}$ & $5,72 \pm 0,33^{\mathrm{a}}$ & $5,70 \pm 0,40^{\mathrm{a}}$ \\
\hline Peso da carcaça quente $(\mathrm{kg})$ & $14,34 \pm 0,69^{\mathrm{a}}$ & $14,19 \pm 0,84^{\mathrm{a}}$ & $14,06 \pm 0,68^{\mathrm{a}}$ & $14,24 \pm 0,78^{\mathrm{a}}$ \\
\hline Peso da carcaça fria $(\mathrm{kg})$ & $14,03 \pm 0,66^{\mathrm{a}}$ & $13,86 \pm 0,80^{\mathrm{a}}$ & $13,71 \pm 0,74^{\mathrm{a}}$ & $13,89 \pm 0,78^{\mathrm{a}}$ \\
\hline Perda de peso por resfriamento $(\mathrm{kg})$ & $2,14 \pm 1,36^{\mathrm{a}}$ & $2,13 \pm 1,08^{\mathrm{a}}$ & $2,55 \pm 1,43^{\mathrm{a}}$ & $2,46 \pm 1,42^{\mathrm{a}}$ \\
\hline Rendimento carcaça comercial (\%) & $44,04 \pm 2,15^{\mathrm{a}}$ & $42,70 \pm 1,99^{\mathrm{a}}$ & $42,75 \pm 1,78^{\mathrm{a}}$ & $43,25 \pm 1,76^{\mathrm{a}}$ \\
\hline Condição corporal (1-5) & $2,82 \pm 0,16^{\mathrm{a}}$ & $2,94 \pm 0,19^{\mathrm{a}}$ & $2,91 \pm 0,26^{\mathrm{a}}$ & $2,85 \pm 0,21^{\mathrm{a}}$ \\
\hline Rendimento carcaça verdadeiro (\%) & $51,64 \pm 2,63^{\mathrm{a}}$ & $51,21 \pm 1,97^{\mathrm{a}}$ & $50,77 \pm 1,27^{\mathrm{a}}$ & $51,06 \pm 1,61^{\mathrm{a}}$ \\
\hline Conformação (1-5) & $2,89 \pm 0,32^{\mathrm{a}}$ & $2,94 \pm 0,28^{\mathrm{a}}$ & $2,89 \pm 0,28^{\mathrm{a}}$ & $2,89 \pm 0,25^{\mathrm{a}}$ \\
\hline Acabamento (1-5) & $1,77 \pm 0,27^{\mathrm{a}}$ & $1,79 \pm 0,23^{\mathrm{a}}$ & $1,91 \pm 0,30^{\mathrm{a}}$ & $1,89 \pm 0,23^{\mathrm{a}}$ \\
\hline
\end{tabular}

Médias seguidas de letras distintas, na mesma linha, diferem $(\mathrm{P}<0,05)$, pelo Teste de Tukey.

Ciência Rural, v.34, n.4, jul-ago, 2004. 
FURUSHO (1995), a qual obteve 199,7g, de ganho de peso médio.

O peso ao abate dos animais (Tabela 2) não diferiu $(\mathrm{P}>0,05)$ entre os grupos, deixando as carcaças em igualdade de condições quanto ao seu desenvolvimento. Conforme apresentados na tabela 2 , não houve efeito de tratamento $(\mathrm{P}>0,05)$ sobre o peso de carcaça quente $(14,20 \mathrm{~kg})$ e fria $(13,87 \mathrm{~kg}) \mathrm{e}$ a porcentagem de perda de peso ao resfriamento $(2,32$ $\mathrm{kg}$ ), estando de acordo com os resultados encontrados por MUSALIA et al. (2000) e diferindo dos valores apresentados por MILTON et al. (1997). Os quatro níveis de uréia não diferiram $(\mathrm{P}>0,05)$ para a variável $\mathrm{pH}$ (Tabela 2), que se apresentou dentro do esperado, observando-se queda na curva, indicativo do processo normal de acidificação da carne.

Os rendimentos de carcaça não diferiram $(\mathrm{P}>0,05)$ entre os grupos (Tabela 2), corroborando os resultados de GAILI \& EL-NAIEM (1992) e MUSALIA et al. (2000). Entretanto, diferem dos publicados por MILTON et al. (1997), que verificaram valores diferentes, de acordo com as quantidades de uréia usadas nas dietas. Não foram observadas diferenças $(\mathrm{P}>0,05)$ para a condição corporal entre os grupos, bem como para conformação e acabamento (Tabela 3), mostrando que a utilização da uréia não influenciou a deposição de tecido adiposo na carcaça.

Os componentes não constituintes da carcaça (Tabela 3), são também passíveis de comercialização (DELFA, 1992), e podem sofrer variações de seus pesos, promovendo importantes oscilações no rendimento da carcaça (FERNANDES, 1994). Para esses componentes, não foram observadas diferenças $(\mathrm{P}>0,05)$ entre tratamentos, com exceção do peso da pele, tendo o nível $0 \%(3,55 \mathrm{~kg})$, diferido $(\mathrm{P}<0,05)$ do nível $0,8 \%(4,19 \mathrm{~kg})$. Esta diferença não pode ser atribuída à uréia, tendo em vista a discrepância dos valores promovidos pelos demais teores.

As medidas da carcaça que se encontram na tabela 4, não diferiram $(\mathrm{P}>0,05)$ entre os grupos, exceto para comprimento da perna, tendo os cordeiros do nível 0,8\% $(29,28 \mathrm{~cm})$ apresentado menor valor que os animais do nível $0 \%(30,92 \mathrm{~cm})$. Esta diferença entretanto, não pode ser atribuída ao efeito da dieta. As carcaças não apresentaram diferenças quanto a sua conformação, indicando que o nível de uréia na ração não interferiu no desenvolvimento do animal. Os cordeiros utilizados apresentaram carcaças com perfil subconvexo, o qual configura planos musculares adequados.

$O$ índice de compacidade da carcaça (Tabela 5) não diferiu ( $\mathrm{P}>0,05)$ entre os teores de uréia. Entretanto, para a variável índice de compacidade da perna, o nível $0,8 \%$ diferiu $(\mathrm{P}<0,01)$ dos níveis 0 e $0,4 \%(0,54,0,51$ e 0,51 , respectivamente).

Não foram observadas diferenças $(\mathrm{P}>0,05)$ entre os tratamentos para a área do olho de lombo e as medidas de seu perfil (Tabela 5), corroborando os resultados obtidos por MUSALIA et al. (2000). Isso indica que a quantidade de tecidos dos animais pertencentes aos quatro tratamentos foi igual, não

Tabela 3 - Médias e desvios-padrão para peso $(\mathrm{kg})$ dos componentes não constituintes da carcaça de cordeiros terminados com diferentes níveis de uréia.

\begin{tabular}{|c|c|c|c|c|}
\hline \multirow{2}{*}{ VARIÁVEIS } & \multicolumn{4}{|c|}{ Níveis de uréia (\% na matéria seca) } \\
\hline & 0 & 0,4 & 0,8 & 1,2 \\
\hline Sangue & $1,35 \pm 0,18^{\mathrm{a}}$ & $1,40 \pm 0,12^{\mathrm{a}}$ & $1,32 \pm 0,20^{\mathrm{a}}$ & $1,25 \pm 0,16^{\mathrm{a}}$ \\
\hline Pele & $3,55 \pm 0,46^{\mathrm{a}}$ & $3,90 \pm 0,37^{\mathrm{ab}}$ & $4,19 \pm 0,29^{b}$ & $3,72 \pm 0,54^{\mathrm{ab}}$ \\
\hline Cabeça & $1,81 \pm 0,15^{\mathrm{a}}$ & $1,87 \pm 0,10^{\mathrm{a}}$ & $1,86 \pm 0,09^{\mathrm{a}}$ & $1,78 \pm 0,21^{\mathrm{a}}$ \\
\hline Fígado & $0,58 \pm 0,07^{\mathrm{a}}$ & $0,56 \pm 0,05^{\mathrm{a}}$ & $0,55 \pm 0,06^{\mathrm{a}}$ & $0,60 \pm 0,06^{\mathrm{a}}$ \\
\hline Coração & $0,12 \pm 0,03^{\mathrm{a}}$ & $0,20 \pm 0,03^{\mathrm{a}}$ & $0,20 \pm 0,03^{\mathrm{a}}$ & $0,20 \pm 0,03^{\mathrm{a}}$ \\
\hline Pulmão + Traquéia & $0,70 \pm 0,17^{\mathrm{a}}$ & $0,72 \pm 0,08^{\mathrm{a}}$ & $0,72 \pm 0,08^{\mathrm{a}}$ & $0,70 \pm 0,17^{\mathrm{a}}$ \\
\hline Baço & $0,058 \pm 0,004^{\mathrm{a}}$ & $0,056 \pm 0,008^{\mathrm{a}}$ & $0,058 \pm 0,009^{\mathrm{a}}$ & $0,06 \pm 0,012^{\mathrm{a}}$ \\
\hline Aparelho Urinário & $0,18 \pm 0,05^{\mathrm{a}}$ & $0,16 \pm 0,05^{\mathrm{a}}$ & $0,16 \pm 0,05^{\mathrm{a}}$ & $0,18 \pm 0,05^{\mathrm{a}}$ \\
\hline Rins /gord. perirenal & $0,18 \pm 0,03^{\mathrm{a}}$ & $0,20 \pm 0,03^{\mathrm{a}}$ & $0,21 \pm 0,03^{\mathrm{a}}$ & $0,22 \pm 0,07^{\mathrm{a}}$ \\
\hline Estômagos & $1,18 \pm 0,19^{\mathrm{a}}$ & $1,14 \pm 0,13^{\mathrm{a}}$ & $1,27 \pm 0,13^{\mathrm{a}}$ & $1,12 \pm 0,17^{\mathrm{a}}$ \\
\hline Intestinos & $1,61 \pm 0,20^{\mathrm{a}}$ & $1,47 \pm 0,20^{\mathrm{a}}$ & $1,47 \pm 0,16^{\mathrm{a}}$ & $1,52 \pm 0,21^{\mathrm{a}}$ \\
\hline Testículos & $0,28 \pm 0,04^{\mathrm{a}}$ & $0,29 \pm 0,07^{\mathrm{a}}$ & $0,33 \pm 0,07^{\mathrm{a}}$ & $0,29 \pm 0,07^{\mathrm{a}}$ \\
\hline Patas & $0,82 \pm 0,05^{\mathrm{a}}$ & $0,83 \pm 0,06^{\mathrm{a}}$ & $0,79 \pm 0,06^{\mathrm{a}}$ & $0,80 \pm 0,04^{\mathrm{a}}$ \\
\hline
\end{tabular}

Médias seguidas de letras distintas, na mesma linha, diferem $(\mathrm{P}<0,05)$, pelo Teste de Tukey.

Ciência Rural, v.34, n.4, jul-ago, 2004. 
Tabela 4 - Médias e desvios-padrão para as medidas $(\mathrm{cm})$, índices de compacidade da carcaça $(\mathrm{kg} / \mathrm{cm})$ e da perna $(\mathrm{cm} / \mathrm{cm})$, medidas A e B $(\mathrm{cm}), \mathrm{C}$ e $\mathrm{J}(\mathrm{mm})$ e área de olho de lombo $\left(\mathrm{cm}^{2}\right)$.

\begin{tabular}{|c|c|c|c|c|}
\hline \multirow{2}{*}{ Medidas* } & \multicolumn{4}{|c|}{ Níveis de uréia (\% na matéria seca) } \\
\hline & 0 & 0,4 & 0,8 & 1,2 \\
\hline CEC & $54,06 \pm 1,50^{\mathrm{a}}$ & $54,72 \pm 2,26^{\mathrm{a}}$ & $54,58 \pm 3,79^{\mathrm{a}}$ & $54,96 \pm 2,70^{\mathrm{a}}$ \\
\hline CIC & $47,71 \pm 2,54^{\mathrm{a}}$ & $47,49 \pm 1,70^{\mathrm{a}}$ & $47,34 \pm 2,33^{\mathrm{a}}$ & $46,84 \pm 2,30^{\mathrm{a}}$ \\
\hline $\mathrm{CP}$ & $30,92 \pm 1,67^{\mathrm{b}}$ & $30,28 \pm 0,85^{\mathrm{ab}}$ & $29,28 \pm 0,49^{\mathrm{a}}$ & $30,24 \pm 0,45^{\mathrm{ab}}$ \\
\hline PG & $55,04 \pm 2,87^{\mathrm{a}}$ & $54,22 \pm 2,57^{\mathrm{a}}$ & $54,53 \pm 3,36^{\mathrm{a}}$ & $54,98 \pm 3,64^{\mathrm{a}}$ \\
\hline LG & $15,66 \pm 0,54^{\mathrm{a}}$ & $15,57 \pm 0,39^{\mathrm{a}}$ & $15,81 \pm 0,70^{\mathrm{a}}$ & $15,65 \pm 3,76^{\mathrm{a}}$ \\
\hline PT & $24,13 \pm 0,63^{\mathrm{a}}$ & $24,39 \pm 2,67^{\mathrm{a}}$ & $24,20 \pm 2,93^{\mathrm{a}}$ & $24,49 \pm 2,22^{\mathrm{a}}$ \\
\hline ICC & $0,30 \pm 0,02^{\mathrm{a}}$ & $0,30 \pm 0,02^{\mathrm{a}}$ & $0,29 \pm 0,02^{\mathrm{a}}$ & $0,30 \pm 0,03^{\mathrm{a}}$ \\
\hline ICP & $0,51 \pm 0,04^{\mathrm{a}}$ & $0,51 \pm 0,03^{\mathrm{a}}$ & $0,54 \pm 0,02^{\mathrm{b}}$ & $0,52 \pm 0,02^{\mathrm{ab}}$ \\
\hline Medida A & $5,80 \pm 0,53^{\mathrm{a}}$ & $5,72 \pm 0,46^{\mathrm{a}}$ & $5,46 \pm 0,42^{\mathrm{a}}$ & $5,14 \pm 0,42^{\mathrm{a}}$ \\
\hline Medida B & $2,96 \pm 0,27^{\mathrm{a}}$ & $3,02 \pm 0,26^{\mathrm{a}}$ & $2,95 \pm 0,24^{\mathrm{a}}$ & $3,04 \pm 0,33^{\mathrm{a}}$ \\
\hline Medida C & $1,95 \pm 0,54^{\mathrm{a}}$ & $1,45 \pm 0,52^{\mathrm{a}}$ & $1,86 \pm 1,02^{\mathrm{a}}$ & $1,78 \pm 0,71^{\mathrm{a}}$ \\
\hline Medida J & $4,82 \pm 1,66^{\mathrm{a}}$ & $3,82 \pm 1,54^{\mathrm{a}}$ & $4,70 \pm 1,93^{\mathrm{a}}$ & $4,91 \pm 2,37^{\mathrm{a}}$ \\
\hline A O L & $12,74 \pm 2,73^{\mathrm{a}}$ & $12,77 \pm 4,59^{\mathrm{a}}$ & $11,61 \pm 2,06^{\mathrm{a}}$ & $13,35 \pm 2,39^{\mathrm{a}}$ \\
\hline
\end{tabular}

Médias seguidas de letras distintas, na mesma linha, diferem $(\mathrm{P}<0,05)$, pelo Teste de Tukey.

$\mathrm{CEC}=$ comprimento externo da carcaça; $\mathrm{CIC}=$ comprimento interno da carcaça; $\mathrm{CP}=$ comprimento da perna; $\mathrm{PG}=$ perímetro da garupa; LG = largura da garupa; PT = profundidade toráxica, $\mathrm{ICC}=$ índice de compacidade da carcaça; $\mathrm{ICP}=$ índice de compacidade da perna. Medida A = largura máxima do Longissimus dorsi; ${ }_{2}$ Medida B = profundidade máxima do Longissimus dorsi; Medida C = espessura de gordura sobre o Longissimus dorsi; Medida $\mathrm{J}=$ maior espessura de gordura sobre o Longissimus dorsi; A. O. L= área de olho de lombo.

Tabela 5 - Médias e desvios-padrão para os pesos e porcentagens dos cortes das meias-carcaças .

\begin{tabular}{|c|c|c|c|c|c|}
\hline \multirow{2}{*}{ Variáveis } & & \multicolumn{4}{|c|}{ Níveis de uréia (\% na matéria seca) } \\
\hline & & 0 & 0,4 & 0,8 & 1,2 \\
\hline \multicolumn{2}{|c|}{ Pescoço (kg) } & $0,52 \pm 0,07^{\mathrm{a}}$ & $0,52 \pm 0,09^{\mathrm{a}}$ & $0,53 \pm 0,10^{\mathrm{a}}$ & $0,50 \pm 0,08^{\mathrm{a}}$ \\
\hline \multicolumn{2}{|c|}{$(\%)$} & $7,4 \pm 0,07^{\mathrm{a}}$ & $7,5 \pm 0,09^{\mathrm{a}}$ & $7,7 \pm 0,10^{\mathrm{a}}$ & $7,2 \pm 0,08^{\mathrm{a}}$ \\
\hline \multicolumn{6}{|c|}{ Costela descoberta } \\
\hline & $(\mathrm{kg})$ & $0,40 \pm 0,06^{\mathrm{a}}$ & $0,34 \pm 0,06^{\mathrm{a}}$ & $0,38 \pm 0,08^{\mathrm{a}}$ & $0,41 \pm 0,08^{\mathrm{a}}$ \\
\hline & $(\%)$ & $5,7 \pm 0,06^{\mathrm{a}}$ & $4,9 \pm 0,06^{\mathrm{a}}$ & $5,5 \pm 0,08^{\mathrm{a}}$ & $5,9 \pm 0,08^{\mathrm{a}}$ \\
\hline \multirow[t]{2}{*}{ Costela } & $(\mathrm{kg})$ & $0,68 \pm 0,09^{\mathrm{a}}$ & $0,62 \pm 0,12^{\mathrm{a}}$ & $0,68 \pm 0,06^{\mathrm{a}}$ & $0,69 \pm 0,09^{a}$ \\
\hline & $(\%)$ & $9,7 \pm 0,09^{\mathrm{a}}$ & $8,9 \pm 0,12^{\mathrm{a}}$ & $9,9 \pm 0,06^{\mathrm{a}}$ & $9,9 \pm 0,09^{\mathrm{a}}$ \\
\hline \multirow[t]{2}{*}{ Paleta } & $(\mathrm{kg})$ & $1,42 \pm 0,09^{\mathrm{a}}$ & $1,42 \pm 0,07^{\mathrm{a}}$ & $1,35 \pm 0,13^{\mathrm{a}}$ & $1,43 \pm 0,08^{a}$ \\
\hline & $(\%)$ & $20,2 \pm 0,09^{\mathrm{a}}$ & $20,5 \pm 0,07^{\mathrm{a}}$ & $19,7 \pm 0,13^{\mathrm{a}}$ & $20,6 \pm 0,08^{a}$ \\
\hline \multirow[t]{2}{*}{ Baixos } & $(\mathrm{kg})$ & $0,85 \pm 0,10^{\mathrm{a}}$ & $0,87 \pm 0,10^{\mathrm{a}}$ & $0,83 \pm 0,09^{\mathrm{a}}$ & $0,81 \pm 0,08^{\mathrm{a}}$ \\
\hline & $(\%)$ & $12,1 \pm 0,10^{\mathrm{a}}$ & $12,5 \pm 0,10^{\mathrm{a}}$ & $12,1 \pm 0,09^{\mathrm{a}}$ & $11,7 \pm 0,08^{\mathrm{a}}$ \\
\hline \multirow[t]{2}{*}{ Lombo } & $(\mathrm{kg})$ & $0,73 \pm 0,10^{\mathrm{a}}$ & $0,67 \pm 0,12^{\mathrm{a}}$ & $0,76 \pm 0,10^{\mathrm{a}}$ & $0,71 \pm 0,13^{\mathrm{a}}$ \\
\hline & $(\%)$ & $10,4 \pm 0,10^{\mathrm{a}}$ & $9,7 \pm 0,12^{\mathrm{a}}$ & $11,1 \pm 0,10^{\mathrm{a}}$ & $10,2 \pm 0,13^{\mathrm{a}}$ \\
\hline \multirow[t]{2}{*}{ Pernil } & $(\mathrm{kg})$ & $2,38 \pm 0,16^{\mathrm{a}}$ & $2,43 \pm 0,20^{\mathrm{a}}$ & $2,29 \pm 0,22^{\mathrm{a}}$ & $2,35 \pm 0,13^{\mathrm{a}}$ \\
\hline & $(\%)$ & $33,9 \pm 0,16 a$ & $35,1 \pm 0,20 \mathrm{a}$ & $33,4 \pm 0,22 \mathrm{a}$ & $33,8 \pm 0,13 a$ \\
\hline
\end{tabular}

Médias seguidas de letras distintas, na mesma linha, diferem $(\mathrm{P}<0,05)$, pelo Teste de Tukey.

Ciência Rural, v.34, n.4, jul-ago, 2004. 
tendo havido interferência da quantidade de uréia da ração, na formação dos tecidos.

Os sete cortes considerados fazem parte de 3 categorias, assim divididas: cortes de $1^{\text {a }}$ (perna, lombo e costelas); cortes de $2^{\text {a }}$ (paleta e costelas descobertas) e cortes de $3^{\text {a }}$ (pescoço e baixos); (SAÑUDO \& SIERRA, 1986), podendo existir diferenças entre eles, de acordo com a raça, peso, sexo, sistema de alimentação e grau de gordura da carcaça (BOCCARD, 1965; SAÑUDO, 1980; LOPEZ, 1987). Porém, constata-se que não houve diferenças $(\mathrm{P}>0,05)$ entre os distintos níveis de uréia, para os pesos e rendimentos dos cortes das meiascarcaças.

Os custos das dietas foram, em reais, $\mathrm{R} \$$ 0,$35 ; \mathrm{R} \$ 0,33 ; \mathrm{R} \$ 0,29$ e R \$ 0,27/kg, para os níveis de uréia $0 ; 0,4 ; 0,8$ e $1,2 \%$, respectivamente. Observou-se diminuição do preço das rações, conforme foi aumentada a quantidade de uréia, resultado que se encontra em conformidade com os obtidos por INAL \& TUNCER (1992) e MUSALIA et al. (2000). Isto acontece porque a uréia tem um grande equivalente protéico e um preço inferior à proteína verdadeira, viabilizando sua utilização nos sistemas de confinamento, nos quais a alimentação responde por grande parte do custo total de produção.

\section{CONCLUSÕES}

A elevação dos teores de uréia, em substituição à proteína verdadeira, não afetou o desempenho dos cordeiros, a curva de decréscimo do $\mathrm{pH}$ muscular, tampouco os caracteres da carcaça e dos demais componentes corporais. Não houve efeito dos teores de uréia utilizados na alimentação de cordeiros sobre a morfometria e proporção dos cortes das carcaças. Recomenda-se a utilização de 1,2\% de uréia na matéria seca total, tendo em vista o menor custo apresentado.

\section{REFERÊNCIAS BIBLIOGRÁFICAS}

BOCCARD, R. Age and meat production. Commu. Inter-meet. Meat for food, Max-plank-institut, Merieusee. Z Tierzücht $\mathbf{n}$ Zücht Biol, v.82, n.3, p.271-285.

COLOMER-ROCHER, F.; ESPEJO, M.D. Determinación del peso optimo de sacrifício de los corderos procedentes del cruzamiento Manchego x Rasa Aragonesa en función del sexo. Información Técnica Econônica Agrária,v.6, p.219-2 35, 1972.

COLOMER-ROCHER, F. Estudio de los parametros que definem los caracteres cuantitativos y cualitativos de las canales. In: CURSO INTERNACIONAL SOBRE PRODUCCIÓN DE
CARNE Y LECHE CON BASE EN PASTOS Y FORRAGES, 1988, La Coruña, Espanha. Proceedings... Espanha, 1988. 108p.

DELFA, R. Clasificación de canales ovinas en la C.E.E. - EI quinto cuarto. N.i.: Diputación General de Aragon, Departamento de Agricultura, Ganaderia y Montes, Dirección General de Promoción Agraria, 1992. 114p.

FERNANDES, S. Peso vivo ao abate e características da carcaça de cordeiros da raça Corriedale e mestiços Ile de France $\mathbf{x}$ Corriedale, recriados em confinamento. 1994. 82f. Dissertação (Mestrado em Zootecnia) - Faculdade de Medicina Veterinária e Zootecnia, UNESP.

FURUSHO, I.F. Efeito da utilização da casca de café, "in natura" e tratada com uréia, sobre o desempenho e características de carcaça de cordeiros terminados em confinamento. 1995. 64f. Dissertação (Mestrado em Zootecnia) - Universidade Federal de Lavras.

FURLAN, L.R. Alimentação e nutrição de animais de cabanha. In: SIMPÓSIO PAULISTA DE OVINOCULTURA, 1., 1988, Botucatu. Anais... Botucatu : Fundação Cargill/FMVZ-UNESP, 1988. p.57-63.

GAILI, E.S.E.; EL-NAIEM, A.A. Effects on performance and carcass quality of feeding date syrup in drinking water as a substitute for barley in rations for lambs. Indian Journal of Animal Sciences, v.62, n.8, p.785-786, 1992.

GARCIA, C.A. Avaliação do resíduo de panificação "biscoito" na alimentação de ovinos e nas características quantitativas e qualitativas da carcaça. 1998. 78f. Dissertação (Mestrado em Zootecnia) - Faculdade de Ciências Agrárias e Veterinárias, UNESP.

INAL, F.; TUNCER, S.D. The possibilities of using tapioca as a source of energy with different nitrogen sources for lamb feeding. Hayvancilik Arastirma Dergisi, v.2, n.1, p.9-14, 1992. (Abstract...).

LOPEZ, M. Calidad de la canal y de la carne en los tipos lechal, ternasco y cordero de la raza Lacha y estudio de su desarrollo. 1987. 465f. Tesis Doctoral (Doctorado em Veterinaria) - Facultad de Veterinaria, Universidad de Zaragoza.

MILTON, C.T.; BRANDT, R.T.; TITGEMEYER, E.C. Urea in dry-rolled corn diets: finishing steer performance, nutrient digestion, and microbial protein production. Journal Animal Science, v.75, n.5, p.1415-24, 1997.

MUSALIA, L.M. et al. Urea-treated neem (Azadirachta indica A. juss) seed kernel cake as a protein supplement for lambs. Small Ruminant Research, v.35, p.107-116, 2000.

SAÑUDO, C. Calidad de la canal y de la carne en el ternasco aragonés. 1980. 337f. Tesis de Doctoral (Doctorado em Veterinaria) - Facultad de Veterinaria, Universidad de Zaragoza.

SAÑUDO, C.; SIERRA, I. Calidad de la canal en la especie ovina. Ovino, n.1, p.127-53, 1986.

SAÑUDO, C.A. La calidad organoléptica de la carne (IV): especial referencia a especie ovina. Mundo Ganadero, v.2, p.67-69, 1993.

SAS Institute. SAS procedures guide. Realise 6.3ed. Cary, 1986. 441p. 